\title{
A Case Of Bilateral Manual Eye-Gouging Of A British Soldier
}

\author{
G Clare, T Poole, J Govan
}

\begin{abstract}
Peacetime assault-related injuries amongst soldiers are common. Whilst the majority of incidents of assault do not result in permanent physical incapacity, some may be devastating, ruining careers and lives. Here we describe one such injury. There is no national register of such injuries; they may, therefore, be under-reported.
\end{abstract}

\section{Introduction}

Manual gouging of another's eyes is a rare assault referenced in mythology and isolated case reports $(1,2)$. We present the case of a British soldier permanently blinded during such an assault by a fellow soldier. The patient sustained bilateral symmetrical globe rupture injuries from finger-gouging.

\section{Case Report}

On his twenty-sixth birthday a guardsman was brought to casualty with severely swollen orbits, facial bruising and a reduced Glasgow Coma Score. No clear history was available and visual acuities could not be assessed. As a brain injury was suspected, he was intubated and a CT scan was requested. This demonstrated the presence of a fluid level in both eyes, suggesting haemorrhage; optic nerves were intact (Figure1). An ophthalmological examination revealed extensive orbital oedema, bilateral corneal oedema, bilateral total hyphaemae and the absence of light reflexes in both eyes. The eyes were soft and the fundi could not be visualized due to the extensive haemorrhage and oedema.

Email: gerry.clare@virgin.net

Mr Tom Poole BSc FRCOphth

Corneal Fellow

Moorfields Eye

Hospital, 162 City

Road, EC1V 2PD.

Mr James Govan

MRCP FRCS

FRCOphth

Consultant

Ophthalmologist

Frimley Park Hospital, Portsmouth Road, Camberley, Surrey, GU15 5UJ.

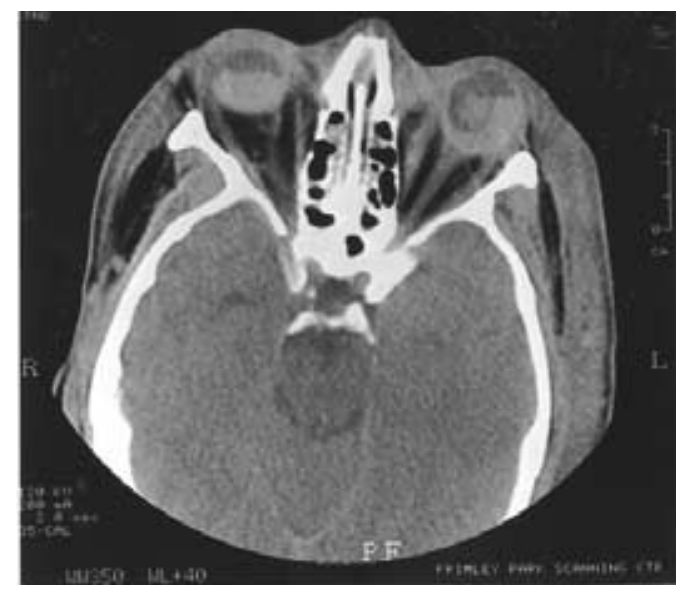

Fig 1: An orbital CT scan demonstrating haemorrhagic fluid levels in both globes.
It emerged that a fellow guardsman, under investigation for psychiatric illness, had used both his index fingers to simultaneously gouge both the patient's eyes during an altercation. The assailant described reaching into the medial aspect of the orbits as far as his own proximal interphalangeal joints. Both soldiers had been drinking alcohol.

Examination of the ocular injuries under general anaesthesia revealed virtually identical $5-6 \mathrm{~mm}$-long scleral lacerations in each eye $4 \mathrm{~mm}$ posterior to the medial insertion of the superior rectus muscle. An intact crystalline lens was found behind the globe adjacent to the right medial rectus. Blood exuded from both the scleral rupture sites, with no choroid or retina visible at the edges of the wounds. Iris tissue was discernible in the anterior chambers. Choroidal pigment was found outside the rupture site in the right eye.

Primary repair of the scleral ruptures was undertaken. Post-operatively, there was no perception of light in either eye.

\section{Discussion}

Finger-gouging of another's eyes is a rare form of severe orbital trauma, and cases resulting in total loss of vision from bilateral globe rupture are particularly rare (3).This is in contrast with auto-enucleation, which is more frequently reported $(4,5)$. The symmetrical pattern of injuries seen in this example of simultaneous bilateral gouging is striking.

Globe rupture is to be differentiated from laceration with a sharp object; it occurs when an external blunt force elevates intraocular pressure sufficiently as to cause the globe to burst. Depending on the population studied, it may occur most often in domestic occupational and sports injuries, or more severely in assault and vehicle accidents $(6,7)$. Rupture is classified as direct, occurring at the site of impact, or indirect, occurring at a scleral site remote to the impact $(7,8)$. It usually occurs at the corneal limbus, or parallel to the equator between the equator and the muscle insertion, where sclera is thinnest $(8,9)$. In this patient rupture sites in the superior nasal quadrant of each eye were observed parallel and close to the equator, possibly as a result of direct mechanical impact of the assailant's fingers. 
A CT scan of the orbits is helpful in the diagnosis and prognosis of ruptured globe injuries (10). In this case, a fine-cut CT scan showed that although the eyes had sustained severe damage, making a positive visual prognosis unlikely, the presence of intact optic nerves suggested that a primary repair might be more appropriate than enucleation, as some degree of visual rescue might still have been possible (1). Optic nerve avulsion, either partial or total, is not uncommon after blunt trauma whether due to gouging or not, and may be missed. Other co-existent orbital injuries may be identified on CT scan; these include orbital floor fractures and avulsed extraocular muscles. Fine cuts are also useful in identifying the presence of small foreign bodies.

Several studies suggest that most victims of assault-related eye injuries are males under thirty, with alcohol and psychiatric illness being frequent aetiologic factors $(11,12)$. A multicentre review of ten cases of eye gouging documented in the United States and Russia found that four of the assailants were psychotic and one mentally retarded; five were psychopathic (13).

Despite overtones of a classic injury, and a number of features common to many assault-related eye injuries, bilateral total loss of vision from finger-gouging is rare.

\section{References}

1. Schneck M, Oshry T, Marcus M, et al. Attempted bilateral manual enucleation during physical assault. Ophthalmology 2003;110(3):575-577.

2. Aboud ND, Shah P and Sullivan F. Assessment and management of manual traumatic enucleation. Aust N Z J Ophthalmol 1995;23:5557.

3. Duke-Elder, S. Text-Book of Ophthalmology. London: Henry Kimpton, 1954; 6: 5872-5884.

4. Taylor, D. Unnatural injuries. Eye 2000;14:123150.

5. Kennedy BL and Feldmann TB. Case presentations and a literature review. Hosp Community Psychiatry 1994; 45:470-474.

6. Dunn ES, Jaeger EA, Jeffers JB, et al. The epidemiology of ruptured globes. Ann Ophthalmol 1992;24:405-410.

7. Bullock JD and Warwar RE. A system for classifying mechanical injuries of the eye (globe). Am f Ophthalmol 1997;125:565.

8. Freitag SK, Eagle RC, Jaeger, et al. An epidemiologic and pathologic study of globes enucleated following trauma. Ophthalmic Surgery 1992;23:409-413.

9. Benson, WE and Jeffers JB. Blunt Trauma. In: Tasman, W and Jaeger EA, eds Duane's Clinical Ophthalmology on CD-ROM. Philadelphia: Lipincott Williams and Wilkins 2000.

10. Joseph DP, Pieramici DJ and Beauchamp NJ. Computed tomography in the diagnosis and prognosis of open-globe injuries. Ophthalmology 2000;107:1899-1906.

11. Dannenberg AL, Parver LM and Fowler CJ. Penetrating eye injuries related to assault. Arch Ophthalmol 1992;110:849-852.

12. Groessl S, Nanda SK and Mieler WF. Assaultrelated penetrating ocular injury. Am $\mathcal{F}$ Ophthalmol 1993;116:26-33

13. Bukhanovsky AO, Hempel A, Ahmed W, et al. Assaultive eye injury and enucleation. J Am Acad Psychiatry Law 1999;27:590-602. 